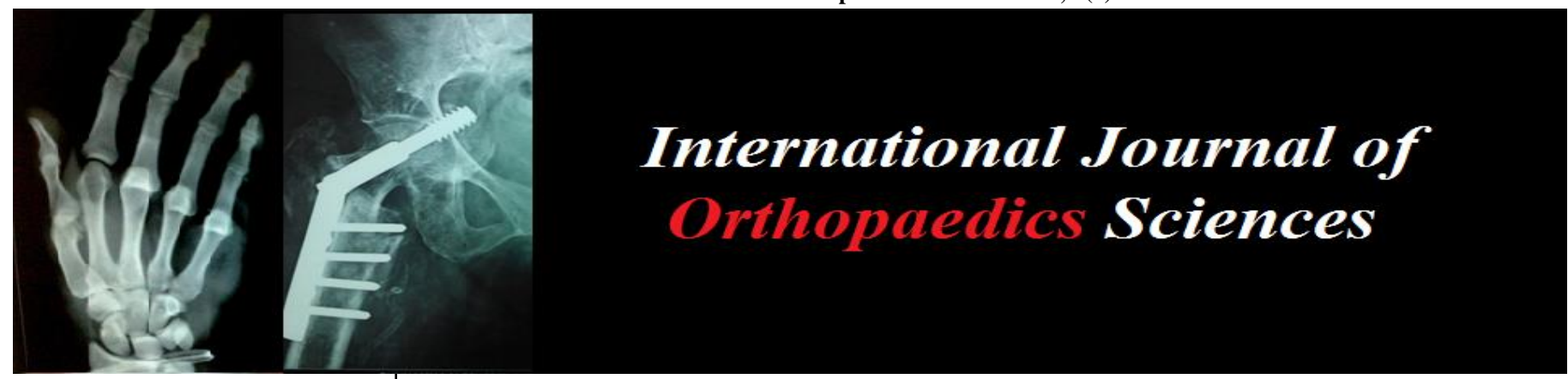

E-ISSN: 2395-1958

P-ISSN: 2706-6630

IJOS 2020; 6(4): 954-960

(C) 2020 IJOS

www.orthopaper.com

Received: 12-08-2020

Accepted: 21-09-2020

Dr. Gautam Chakraverty

M.B.B.S., M.S. (Ortho), B.H.U.,

Consultant Orthopaedist,

Ramakrishna Mission Home of

Service, Varanasi,

Uttar Pradesh, India

Dr. Arun Gupta

M.B.B.S., M.S. (Ortho), OJAS

Hospital, Agra, Uttar Pradesh

India

Dr. Anish Desai

M.D., F.C.P., PGDHEP,

Director, Strategic Medical

Affairs, Nutragenix Healthcare

Pvt. Ltd., Mumbai,

Maharashtra, India

Dr. Sunaina S Anand

Pharm. D, Medical Affairs

Executive, Nutragenix

Healthcare Pvt. Ltd., Mumbai,

Maharashtra, India
Corresponding Author: Dr. Sunaina S Anand Pharm. D, Medical Affairs Executive, Nutragenix Healthcare Pvt. Ltd., Mumbai, Maharashtra, India

\section{Clinical benefits and risk assessment of TriNyros in osteoarthritis of the knee: BRATO evidence generation program}

\author{
Dr. Gautam Chakraverty, Dr. Arun Gupta, Dr. Anish Desai and Dr. \\ Sunaina S Anand
}

DOI: $\underline{\text { https://doi.org/10.22271/ortho.2020.v6.i4n.2444 }}$

\begin{abstract}
Background: Osteoarthritis is a major cause of disability worldwide, especially in older adults. Alternative treatments are preferred due to the cardiovascular and gastrointestinal side effects of nonsteroidal anti-inflammatory drugs (NSAIDs). Nutraceuticals help in balancing anabolic and catabolic processes in the joint tissue, improve redox balance, free-radical scavenging, thus provide cartilage protection. Rosa canina L. (Rosehip), Boswellia serrata and Harpagophytum procumbens (Devil`s claw) extract are being recognized for their anti-inflammatory, antioxidant, analgesic and chondroprotective properties in Osteoarthritis.
\end{abstract}

Aim: A post-marketing clinical evidence generation program was conducted to assess the effectiveness and tolerability of capsule TriNyros in knee osteoarthritis.

Methods: An evidence generation program was conducted in 20 outpatient orthopedic clinics. All patients received TriNyros containing [Rosehip $275 \mathrm{mg}$, Irido Force ${ }^{\mathrm{TM}}$ (Devil`s claw extract) $100 \mathrm{mg}$ and Aflapin ${ }^{\circledR} 50 \mathrm{mg}$ ] twice daily for 90 days. Patients were on their regular anti-arthritic treatment and TriNyros was added as an adjuvant to their regular treatment. Clinical assessment of symptoms included palpation pain, limitation of mobility, joint crepitus, swelling and redness was assessed. Osteoarthritis symptoms were measured using Western Ontario and McMaster Universities Osteoarthritis Index (WOMAC), 3- pointer and $10 \mathrm{~mm}$ visual analogue scale (VAS). Hematological and serum biomarkers were analyzed to evaluate tolerability of TriNyros.

Results: A total of 105 patients, comprising 42 women and 63 men mostly belonging to the age group of 58-65 years $(39.05 \%)$ enrolled in the program. Significant reduction in WOMAC scores was seen in majority of the patients at day $15,30,60$ and $90(P<0.0001)$. WOMAC scores for joint pain declined by $58.82 \%$ (mean \pm SD: $66.43 \pm 11.97$ to $27.35 \pm 7.92$ ) at the end of 3 months ( $p<0.0001$ ). The reduction was significant from the $15^{\text {th }}$ day itself $(\mathrm{p}=0.02)$ and continued till day 90 . Pain measured by VAS significantly reduced by $67 \%(7.11 \pm 1.56$ to $2.34 \pm 0.72, P<0.0001)$ at day 30,60 and 90 . At the end of the treatment, palpation pain, limitation of mobility, joint crepitus, swelling and redness showed significant improvements $(P<0.01)$. Intake of concomitant medication was observed in $32(30.48 \%)$ patients. No major adverse reactions were reported.

Conclusion: Overall, this preliminary study concluded that TriNyros was found to be effective and well tolerated in reducing pain and improving general condition in osteoarthritis of the knee.

Keywords: Nutraceutical, osteoarthritis, aflapin, rosehip, devil`s claw, real-world evidence (RWE)

\section{Introduction}

Core tip: Osteoarthritis (OA) of the knee is a major cause of disability in older adults worldwide, with a prevalence of $28.7 \%$ in India. It affects the hands, feet, spine, and large weight-bearing joints, such as the hips and knees. Risk factors include age, female sex, obesity, sedentary people, knee mal-alignment, frequent kneeling, squatting, climbing, heavy lifting, high-impact sports resulting in knee injury ${ }^{[1,2]}$. Pathological changes include softening, ulceration, and finally, disintegration of the articular cartilage ${ }^{[3]}$. The key comorbidities associated with OA are stroke, peptic ulcer and metabolic syndrome that includes hypertension, diabetes mellitus, dyslipidemia, hypothyroidism and osteoporosis ${ }^{[4]}$. Clinical diagnosis is based on symptoms (pain, brief morning stiffness, and functional limitations) along with a physical examination (restricted or painful movement, joint tenderness, crepitus and bony enlargement). 
American College of Rheumatology (ACR) or the European League against Rheumatism for knee osteoarthritis (EULAR) are recommended for appropriate diagnosis ${ }^{[5]}$.

The onset of $\mathrm{OA}$ is a consequence of synovial inflammation influenced 5-lipoxygenase (5-LOX) pathway, proinflammatory cytokines and matrix metalloproteinases (MMPs) enzymatically degenerate cartilaginous matrix substances thereby aggravating the condition ${ }^{[6-8]}$. Failure of NSAIDS, viscosupplementation and intra-articular corticosteroids and other non-pharmacological interventions is attributed to a lack of efficacy and more adverse effects ${ }^{[9-}$ 12]. Alternative treatments are preferred due to the cardiovascular and gastrointestinal side effects of NSAIDs [13]

Nutraceuticals are dietary compounds that balance anabolic and catabolic signals in the joint tissue ${ }^{[14]}$. Glucosamine, chondroitin sulfate, methylsulfonylmethane, Boswellia, Curcumin, Ginger and collagen peptide have been tested in the treatment of knee OA with results showing ambiguous efficacy, poor bioavailability or poor tolerability ${ }^{[15-19]}$. Raju Vaishya et al. in their review mentioned Aflapin and Rosehip in the top 10 nutraceuticals used for Knee Osteoarthritis in India ${ }^{[3]}$.

Rosehips (RHP) are the berry fruits of Rosa canina L. Galactolipid (2S)-1, 2-di-O-[(9Z, 12Z, 15Z)-octadeca-9, 12, 15-trienoyl]-3-O- $\beta$ D-galactopyranosyl glycerol (GLGPG) is the active constituent. RHP and GLGPG function in downregulating catabolic processes that causes $\mathrm{OA}^{[20]}$.

IridoForce ${ }^{\mathrm{TM}}$ is obtained from the extract of Harpagophytum procumbens (Devils claw), as traditional South African plant. Iridoid glycosides, primarily harpagoside, is the active constituent of IridoForce ${ }^{\mathrm{TM}}$. Harpagoside and procumbide, sugars, triterpenoids, phytosterols, aromatic acids and flavonoids such as luteolin and kaempferol are the other major constituents. Anti-inflammatory action of Harpagoside is due to inhibition of inducible nitric oxide (iNOS), cyclooxygenase (COX-2) expression by suppressing Tumor Necrosis Factor alpha (TNF- $\alpha)$ via nuclear factor kappa $\beta$ $(\mathrm{NF}-\kappa \beta)$ pathway. Peripheral analgesic action and antioxidant action is dose-dependent. Chondroprotective action is conferred by inhibiting COX-2 and iNOS among other inflammatory mediators. Matrix metalloproteinases (MMPs) and elastase responsible for cartilage degradation are inhibited [21]

Aflapin ${ }^{\circledR}$ is a novel composition extracted from Boswellia serrata gum resin. (Indian frankincense or Gajabhakshya). Boswellic acid (BAs) is the main constituent contributing to anti-inflammatory property ${ }^{[22]}$. 5-LOX inhibition and suppressing leukotrienes is the main mechanism for reducing inflammation ${ }^{[23]}$. 3-O-acetyl-11-keto- $\beta$-boswellic acid (AKBA) is the most potent 5-LOX inhibitor among other BAs $[24,25]$. Similarly, Aflapin ${ }^{\circledR}$ is a selective 5-LOX inhibitor ${ }^{[26]}$. Aflapin ${ }^{\circledR}$ has shown better bio-availability than Boswellia ${ }^{[1]}$.

There is no existing data for the use of TriNyros in the treatment of osteoarthritis of the knee. This was the preliminary study to be undertaken to assess effectiveness and tolerability of TriNyros (Aflapin ${ }^{\circledR}$, IridoForce ${ }^{\mathrm{TM}}$ and Rosehip) as an add-on treatment for patients who are on standard treatment and had inadequately controlled symptoms.

\section{Methods}

BRATO was a post-marketing clinical evidence generation program. The evaluation protocol was approved by SurakshaIndependent Ethics Committee, Mumbai. Participants were recruited from September 2019 until March 2020 and followed up for 3 months. All participants gave written informed consent before the screening.

\section{Setting and participants}

Patients were recruited from 20 separate outpatient orthopedic clinics. Eligible patients were aged 19-75 years of age; clinical diagnosis of osteoarthritis of the knee based on the American College of Rheumatology (ACR) criteria and at least moderate pain in the knee (rated at 5 or greater by the subject on a visual analog scale) during the most painful knee movement during the last month. Patients who were inadequately controlled with NSAIDs were enrolled.

Exclusion criteria were acute joint trauma of the knee; uncontrolled diabetes and hypertension; any severe cardiac, renal and hepatic disease, or end organ damage; pregnancy or lactation; a history of allergy against herbal products, or NSAIDs.

\section{Intervention}

Subjects were instructed to take TriNyros capsule [Rosehip $275 \mathrm{mg}$, IridoForce ${ }^{\mathrm{TM}}$ (Devil's claw extract) $100 \mathrm{mg}$ and Aflapin $^{\circledR} 50 \mathrm{mg}$ ] twice daily for 3 months.

Patients were on their regular anti-arthritic treatment and TriNyros was added as an adjuvant to their regular treatment. Patients were advised not to take other Ayurvedic/herbal/homeopathic dietary supplements or any alternative therapies during the treatment period. A record of these medications was maintained.

\section{Outcomes and Follow-up}

Data were collected using standardized case report forms at screening; baseline; day 15, 30, 60 and 90. The primary outcome measures included OA symptoms, WOMAC score and pain. Clinical assessment of symptoms which included pain on palpation, limitation of mobility, joint crepitus, swelling and redness were assessed using a 4-point-scale $(0=$ not at all, $1=$ mild, $2=$ moderate, $3=$ severe $)$. Symptoms of osteoarthritis were assessed by the Western Ontario and McMaster Universities (WOMAC) osteoarthritis index and a higher WOMAC score represents worse symptom severity. The patients used the $10 \mathrm{~mm}$ visual analog scale (VAS) to assess pain. WOMAC, pain and OA symptoms were assessed at day $0,15,30,60$ and 90 .

Hematological and serum biomarkers (ESR, CRP, CBC, SGOT, SGPT, urea, creatinine) and occurrence of adverse events were secondary outcome measures assessed at the beginning and end of the treatment. Blood pressure, heart rate and respiratory rate were monitored and measured during each visit.

\section{Statistical analysis \\ Sample size considerations}

This was the first clinical evidence generation program to evaluate the effectiveness and tolerability of TriNyros in knee osteoarthritis with no previous data available. A sample size of 100 participants from 20 centers ( 5 from each site) was considered adequate to address the evaluation objectives.

\section{Effectiveness and Tolerability analysis}

The effectiveness and tolerability data had been analyzed using 'Intention to Treat' analysis. Demographic data were analyzed using descriptive statistics. The Difference in clinical response before and after the treatment was assessed for normal distribution using the Kolmogorov Smirnov test. The paired Student's t-test was also used. For distribution-free 
data, the Mann Whitney $\mathrm{U}$ test was used. All tests were carried out at $5 \%$ significance.

The statistical methods of this study were reviewed by Markov Analytics, Pune.

\section{Results}

A total of 105 patients, comprising 42 women and 63 men were enrolled in the program. Maximum patients $(39.05 \%)$ belonged to the age group of $58-65$ years $(n=41 / 105)$ as shown in Figure 1.

All patients received TriNyros capsule. The mean history of analgesic use (before treatment) was observed to be $42.86 \%$ $(\mathrm{n}=45)$. Intake of concomitant medication was observed in 32 $(30.48 \%)$ patients.

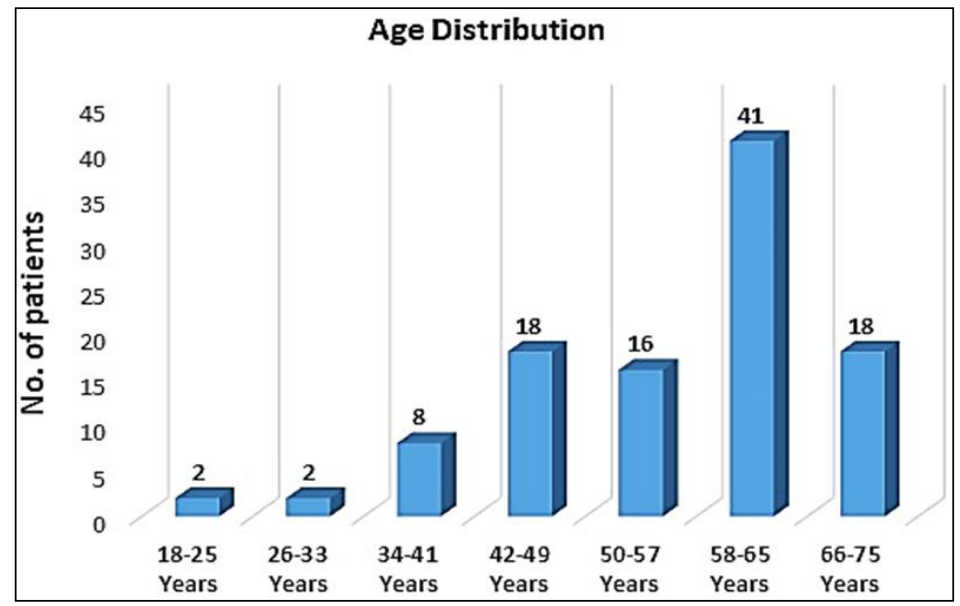

Fig 1: Age distribution of patients

\section{WOMAC score}

Before and after treatment scores for WOMAC, VAS and other clinical assessment are given below in table 1 .

WOMAC scores for joint pain declined by $58.82 \%$ (mean \pm SD: $66.43 \pm 11.97$ to $27.35 \pm 7.92$ ) at the end of 3 months ( $p<$ $0.0001)$. The reduction was significant from the $15^{\text {th }}$ day itself $(\mathrm{p}=0.02)$ and continued till day 90 as depicted in Figure 2.

Pain assessed by the patients using 10mm VAS was declined by $67.07 \%$ (mean \pm SD: $7.11 \pm 1.56$ to $2.34 \pm 0.72$ ) at the end of 3 months $(p<0.0001)$. The reduction was significant from the $30^{\text {th }}$ day itself $(\mathrm{p}=0.005)$ and continued till day 90 as depicted in Figure 3.

Osteoarthritic symptoms such as palpation pain, limitation of mobility, joint crepitus, swelling and redness reduced in all patients after treatment with TriNyros $(p<0.01)$ as shown in table 1. Significant reduction in pain was observed from the $30^{\text {th }}$ day itself $(p<0.001)$. There was significant reduction in palpation pain $(82.98 \%)$ followed by redness $(76.32 \%)$, swelling $(59.26 \%)$ and joint crepitus $(53.90 \%)$ as shown in Figure 4 . There was less reduction in limitation of mobility $(12.12 \%)$, yet it was significant $(p<0.01)$.

Table 1: Primary outcome measures at baseline and after 90 days of treatment with TriNyros

\begin{tabular}{|c|c|c|c|c|}
\hline Sr. No. & Parameter & $\begin{array}{c}\text { Before TriNyros } \\
\text { (Day 0) }(\text { Mean } \pm \text { S.D. })\end{array}$ & $\begin{array}{c}\text { After TriNyros } \\
\text { (Day 90) }(\text { Mean } \pm \text { S.D.) }\end{array}$ & $\begin{array}{c}\text { \% Change after 90 } \\
\text { days of treatment }\end{array}$ \\
\hline 1. & Pain of Palpation & $1.34 \pm 0.48$ & $0.23 \pm 0.42$ & $82.98 \%^{\mathrm{b}}$ \\
\hline 2. & Limitation of Mobility & $0.94 \pm 0.23$ & $0.83 \pm 0.38$ & $12.12 \%^{\mathrm{a}}$ \\
\hline 3. & Joint Crepitus & $1.34 \pm 0.63$ & $0.62 \pm 0.80$ & $53.90 \%^{\mathrm{b}}$ \\
\hline 4. & Swelling & $1.03 \pm 0.56$ & $0.42 \pm 0.50$ & $59.26 \%^{\mathrm{b}}$ \\
\hline 5. & Redness & $0.72 \pm 0.74$ & $0.17 \pm 0.38$ & $76.32 \%^{\mathrm{b}}$ \\
\hline 6. & WOMAC Score & $66.43 \pm 11.97$ & $27.35 \pm 7.92$ & $58.82 \%^{\mathrm{b}}$ \\
\hline 7. & VAS Score & $7.11 \pm 1.56$ & $2.34 \pm 0.72$ & $67.07 \%^{\mathrm{b}}$ \\
\hline
\end{tabular}
$P<0.01 ; P<0.0001$

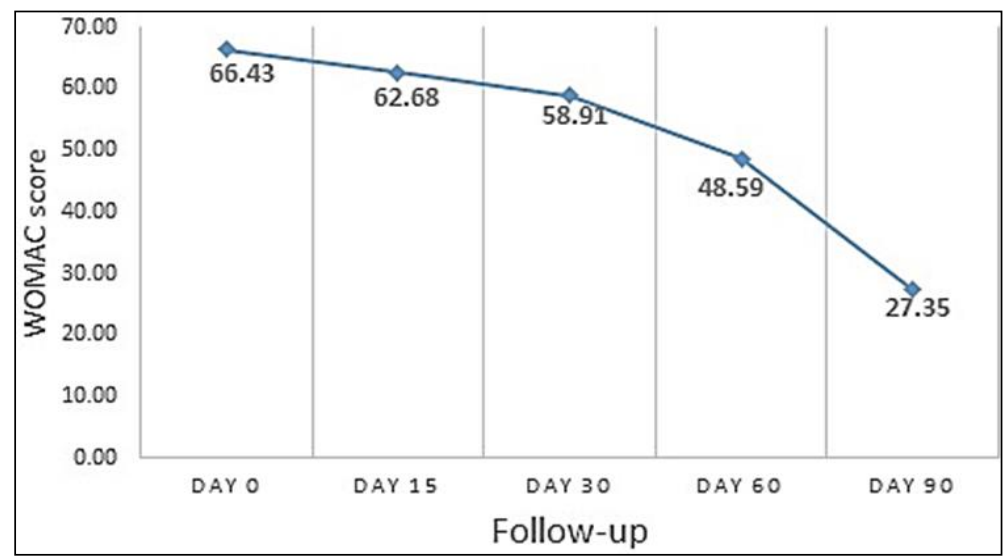

Significant reduction in WOMAC score on day 15, 30, 60 and $90(p<0.05)$

Fig 2: Reduction in WOMAC Score after treatment with TriNyros 


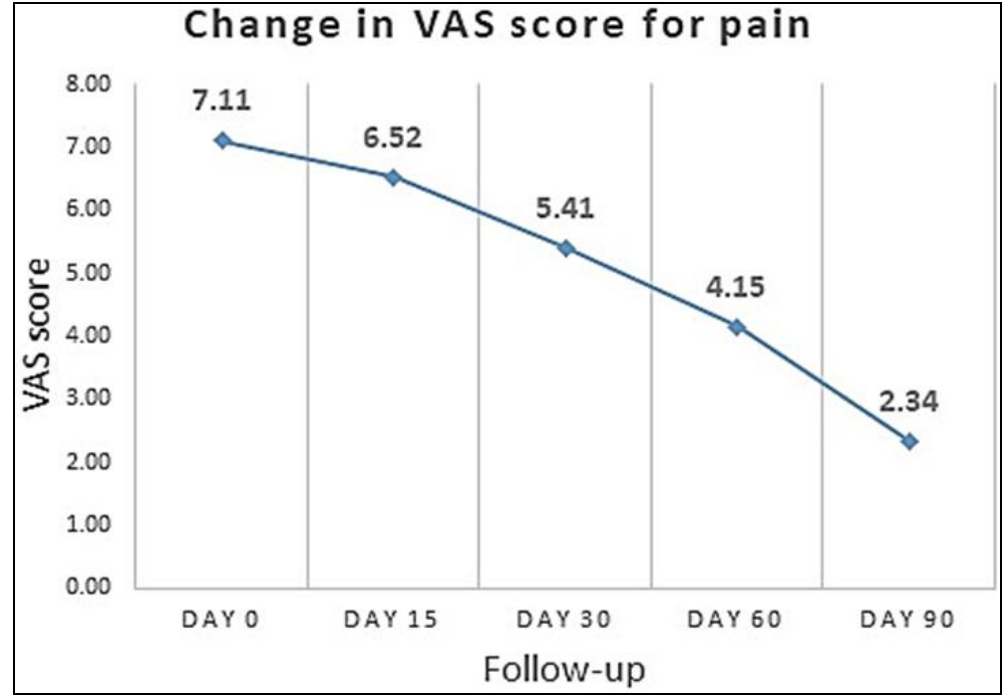

Significant reduction in pain on day 15, 30, 60 and $90(p<0.01)$.

VAS: Visual Analogue Scale

Fig 3: Reduction in Pain assessed by visual analog scale (VAS) after treatment with TriNyros

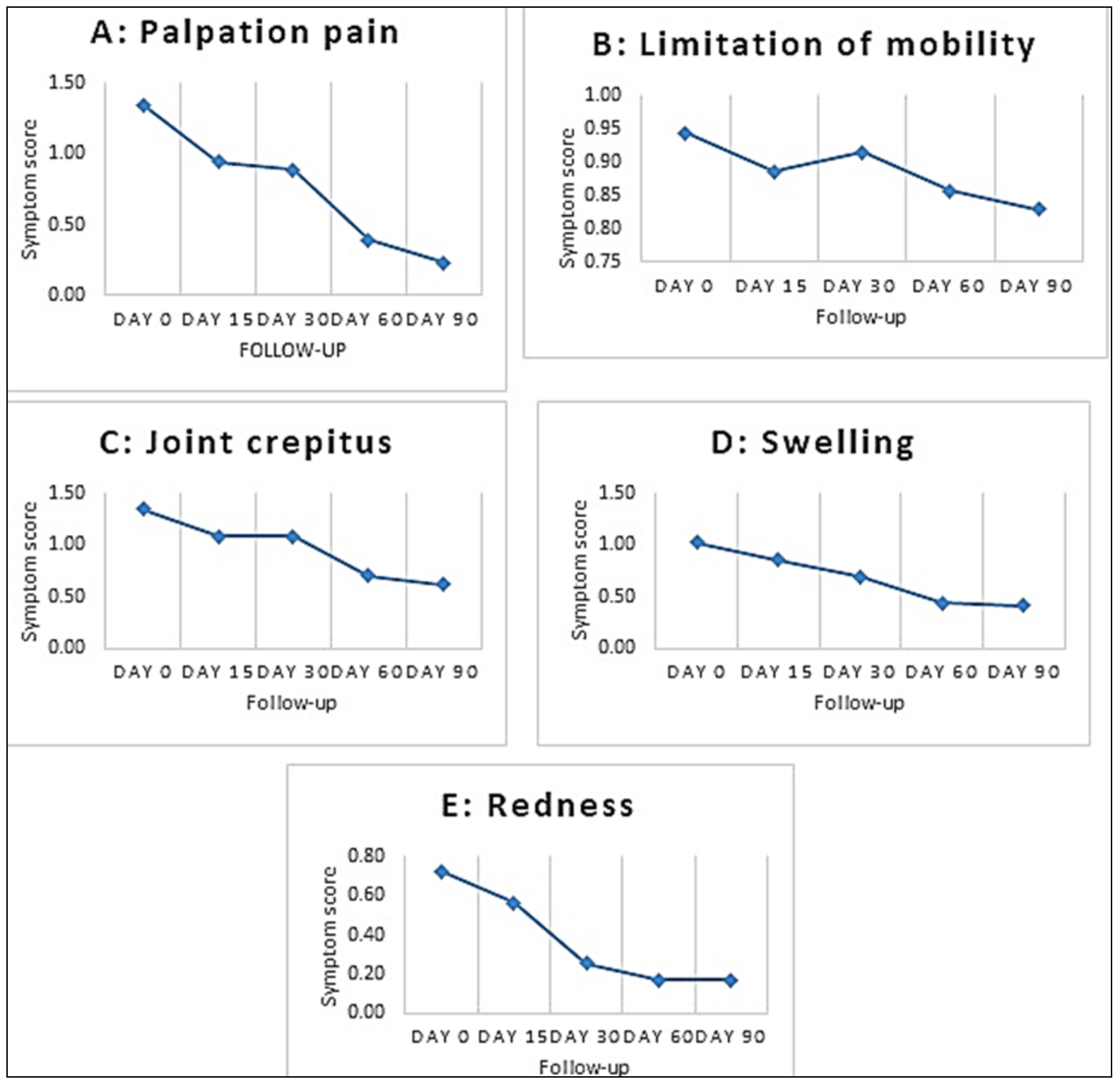

Fig 4: Change in clinical assessment scores of OA symptoms

\section{Safety}

ESR reduced significantly by $17.31 \%(20.80 \pm 6.14$ to 17.20 $\pm 5.72 \mathrm{~mm} / \mathrm{hr}, p<0.05)$. Lymphocytes significantly reduced by $44.93 \%(P<0.001)$. There was no significant change in other biomarkers or vitals (blood pressure, heart rate and respiratory rate). The data suggests that the treatment was safe and well tolerated in OA patients. No major adverse events were observed. 


\section{Discussion}

This is the first clinical evidence generation program to evaluate the effectiveness and tolerability of TriNyros consisting of Rosehip, Aflapin ${ }^{\circledR}$ (AKBA) and IridoForce ${ }^{\mathrm{TM}}$ (harpagoside) in patients suffering from osteoarthritis of the knee. All patients reported significant reduction $($ mean $=$ $58.82 \%, p<0.0001)$ in WOMAC scores after 3 months of active treatment. Pain assessed by the patients was significantly reduced $(p<0.0001)$. Presumably these improvements might have occurred through down regulation of cartilage degrading enzymes (MMP-3) and antiinflammatory action (inhibition of 5-LOX) as discussed earlier. Indeed, we were able to show that ESR reduced after treatment. Hematological and serum biochemical parameters remained unchanged. In addition, no major adverse effect were reported by the subjects. Taken together, these observations further demonstrate that TriNyros capsule is effective in reducing OA symptoms and improves WOMAC score.

Efficacy and safety of Boswellia and its extract in OA is well established in a meta-analysis of 28 clinical trials ${ }^{\text {[27] }}$. There exist only two clinical trials for Aflapin ${ }^{\circledR}$ in OA. The first clinical study involving Aflapin ${ }^{\circledR}$ was conducted in 40 subjects with OA of the knee who received either $100 \mathrm{mg}$ of Aflapin ${ }^{\circledR}$ or $100 \mathrm{mg}$ of 5-Loxin or a placebo. Aflapin ${ }^{\circledR}$ exhibited better 5-lipoxygenase inhibitory activity, MMP-3 inhibition and oral bioavailability. WOMAC pain score reduced significantly ${ }^{[28]}$. The second study was a doubleblind, randomized, placebo-controlled study that included 60 subjects with OA of the knee. The subjects received either $100 \mathrm{mg}(\mathrm{n}=30)$ of Aflapin $^{\circledR}$ or placebo $(\mathrm{n}=30)$ daily for 30 days. Aflapin ${ }^{\circledR}$ provided significant improvements in pain and functional ability as early as the $5^{\text {th }}$ day of treatment ${ }^{[29]}$. The safety of Aflapin ${ }^{\circledR}$ was tested using a battery of safety studies and it was found to be safe ${ }^{[30]}$.

IridoForce ${ }^{\mathrm{TM}}$ is patented extract from the secondary roots (storage tubers) of Devil's Claw, due to higher content of harpagoside than its primary roots. A unique patented process allows IridoForce ${ }^{\mathrm{TM}}$ to offer an extract with the highest content of Harpagoside (up to $20 \%$ Harpagoside by HPLC or $40 \%$ by UV). In a review of 28 clinical trials of Devil's claw extracts, two high-quality studies (Lecomte et al. Chantre et $a l$.) indicate that Devil's Claw was effective in reducing pain. Adverse events occurred at a very low rate of about $3 \%$. Mainly mild gastrointestinal effects occurred and were similar with placebo. Long-term use of Devil's claw appears to be safe in the recommended dosage ${ }^{[31]}$.

Dry powder of Rosehips exert anti-inflammatory properties through a reduction in CRP that started after 4 weeks of supplementation in patients with OA ${ }^{[32-36]}$. Rosehips have shown some efficacy in OA of the knee along with a counter reduction in the need of rescue medicine [34]. It has a consistent, moderate efficacy in OA associated pain shortterm clinical trials (3-4 months). Treatment with Rosehips seems safe to administer in humans as adverse events were similar to placebo in the available clinical studies ${ }^{[37]}$.

Some limitations of BRATO should be considered. The program was not designed to evaluate concomitant or rescue medication since it was a post-marketing evidence generation program in the real world scenario to assess effectiveness and tolerability of add-on TriNyros to the existing treatment of knee OA. TriNyros was not compared with NSAIDs or other alternate therapies in this preliminary program. Further studies need to be undertaken to assess TriNyros associated reduction in rescue medication (NSAIDs) in knee OA. There is a need of comparative evaluation between TriNyros and standard treatment. Structure-modifying variables as primary endpoints would help in determining chondroprotection action or disease-modifying property of TriNyros.

\section{Conclusion}

This is the first clinical evidence generation program that supports a potential use of TriNyros, a novel combination containing Aflapin ${ }^{\circledR}$, Rosehip and IridoForce ${ }^{\mathrm{TM}}$ as an adjuvant in the management of $\mathrm{OA}$ of the knee. This novel combination has a multi-factorial mechanism of action that incudes anti-inflammatory, antioxidant, analgesic and chondroprotective action. Aflapin, a constituent of TriNyros is an effective, safe and fast acting intervention in OA conferring significant improvement in pain and functional ability in as early as 5 days of treatment. The current study results also suggest the rapid onset of action and symptom resolution. TriNyros ${ }^{\circledR}$ decreased the pain and discomfort of knee osteoarthritis, improving the patient's general condition with no major adverse events. In the future, generating efficacy and safety data from a multicentric, randomized clinical trial comparing TriNyros and standard treatment options will be vital. Overall, TriNyros is indicated as an addon therapy to NSAIDS in knee OA.

\section{Acknowledgement}

The authors would like to thank the following orthopaedicians that took part in this evidence generation program: Dr. Anoop Agarwal, Dr. Bhaskar Sharma, Dr. Guriqbal Singh Chinna, Dr. HP Singh, Dr. Jatindra Salhotra, Dr. J.S Bhinder, Dr. Parshotam Lal Mahendru, Dr. Prashant Tripathi, Dr. Rajesh Mehta, Dr. Rajesh Singh, Dr. RS Bhaduria, Dr. Sanjay Dhawan, Dr. Sanjeev Garg, and Dr. SDS Manhas.

\section{Funding}

BRATO Evidence Generation Program was sponsored by Nutragenix Healthcare Pvt Ltd.

\section{References}

1. Kumar H, Pal CP, Sharma YK, Kumar S, Uppal A. Epidemiology of knee osteoarthritis using Kellgren and Lawrence scale in Indian population. Journal of Clinical Orthopaedics and Trauma 2020;11:S125-S129. https://doi.org/10.1016/j.jcot.2019.05.019

2. Pal CP, Singh P, Chaturvedi S, Pruthi KK, Vij A. Epidemiology of knee osteoarthritis in India and related factors. Indian Journal of Orthopaedics. 2016; 50(5):518522. https://doi.org/10.4103/0019-5413.189608

3. Vaishya R, Agarwal AK, Shah A, Vijay V, Vaish A. Current status of top 10 nutraceuticals used for Knee Osteoarthritis in India. Journal of Clinical Orthopaedics and Trauma 2018;9(4):338-348. https://doi.org/10.1016/j.jcot.2018.07.015

4. Swain S, Sarmanova A, Coupland C, Doherty M, Zhang W. Comorbidities in Osteoarthritis: A Systematic Review and Meta-Analysis of Observational Studies. Arthritis Care Res (Hoboken) 2020;72(7):991-1000. doi: 10.1002/acr.24008. Epub 2020 Jun 7. PMID: 31207113.

5. Hunter DJ, Bierma-Zeinstra S. Osteoarthritis. The Lancet 2019;393(10182):1745-1759. https://doi.org/10.1016/S0140-6736(19)30417-9

6. Westacott CI, Urban JP, Goldring MB, Elson CJ. The effects of pressure on chondrocyte tumour necrosis factor receptor expression. Biorheology 2002;39:125-132.

7. Fernandes JC, Martel-Pelletier J, Pelletier JP. The role of 
cytokines in osteoarthritis pathophysiology. Biorheology 2002;39:237-246.

8. Dijkgraaf LC, De Bont LG, Boering G, Liem RS. The structure, biochemistry, and metabolism of osteoarthritic cartilage: A review of the literature. J Oral Maxillofac Surg 1995;53:1182-1192.

9. Filardo G, Kon E, Longo UG, Madry H, Marchettini P, Marmotti A et al. Non-surgical treatments for the management of early osteoarthritis. Knee Surgery, Sports Traumatology, Arthroscopy 2016;24(6):1775-1785. https://doi.org/10.1007/s00167-016-4089-y

10. Finsterer J, Mahjoub SZ. Fatigue in healthy and diseased individuals. The American Journal of Hospice \& Palliative Care https://doi.org/10.1177/1049909113494748

11. Kalunian KC. Current advances in therapies for osteoarthritis. Current Opinion in Rheumatology 2016;28(3):246-250. 10.1097/BOR.0000000000000273

12. Bennell KL, Hunter DJ, Hinman RS. Management of osteoarthritis of the knee. BMJ 2012;345:e4934. https://doi.org/10.1136/bmj. e4934

13. Bannuru RR, Schmid CH, Kent DM, Vaysbrot EE, Wong JB, McAlindon TE. Comparative effectiveness of pharmacologic interventions for knee osteoarthritis: A systematic review and network meta-analysis. Annals of Internal Medicine 2015;162(1):46-54. https://doi. org/10.7326/M14-1231

14. Ravalli S, Szychlinska MA, Leonardi RM, Musumeci G. Recently highlighted nutraceuticals for preventive management of osteoarthritis. World Journal of Orthopaedics 2018;9(11):255-261 https://doi.org/10.5312/wjo.v9.i11.255

15. Clegg DO, Reda DJ, Harris CL, Klein MA, O'Dell JR, Hooper MM et al. Glucosamine, chondroitin sulfate, and the two in combination for painful knee osteoarthritis. The New England Journal of Medicine 2006;354(8):795-808. https://doi.org/ 10.1056/NEJMoa052771

16. Liu X, Machado GC, Eyles JP, Ravi V, Hunter DJ. Dietary supplements for treating osteoarthritis: A systematic review and meta-analysis. British Journal of Sports Medicine 2018;52(3):167-175. https://doi. org/10.1136/bjsports-2016-097333

17. Simental-Mendia M, Sanchez-Garcia A, Vilchez-Cavazos F, Acosta-Olivo CA, Pena-Martinez VM, Simental-Mendia LE. Effect of glucosamine and chondroitin sulfate in symptomatic knee osteoarthritis: A systematic review and meta-analysis of randomized placebo-controlled trials. Rheumatology International 2018;38(8):1413-1428.

https://doi.org/10.1007/s00296-018-4077-2

18. Singh JA, Noorbaloochi S, MacDonald R, Maxwell LJ. Chondroitin for osteoarthritis. Cochrane Database of Systematic Reviews 2015. CD005614. https://doi.org/10.1002/14651858.

CD005614.pub2Vangsness, Spiker \& Erickson, 2009

19. Gregory PJ, Sperry M, Wilson AF. Dietary supplements for osteoarthritis. American Family Physician 2008;77(2):177-184.

20. Schwager J, Hoeller U, Wolfram S, Richard N. Rose hip and its constituent galactolipids confer cartilage protection by modulating cytokine, and chemokine expression. BMC Complementary and Alternative Medicine 2011;11:1-14. https://doi.org/10.1186/1472-6882-11-105

21. Harpagophytum procumbens (devil's claw). Monograph.
Altern Med Rev 2008;13(3):248-52. PMID: 18950251

22. Ammon HP, Safayhi H, Mack T, Sabieraj J. Mechanism of anti-inflammatory actions of curcumine and boswellic acids. J Ethnopharmacol 1993; 38:113-9.

23. Ammon HP. Salai guggal-Boswellia serrata: from a herbal medicine to a specific inhibitor of leukotriene biosynthesis. Phytomedicine 1996;3:67-70.

24. Sailer ER, Subramanian LR, Rall B, Hoernlein RF, Ammon HP, Safayhi H et al. Acetyl-11-keto-betaboswellic acid (AKBA): structure requirements for binding and 5-lipoxygenase inhibitory activity. $\mathrm{Br} \mathbf{J}$ Pharmacol 1996;117:615-8.

25. Siddiqui MZ. Boswellia Serrata, a potential antiinflammatory agent: an overview. Indian J Pharm Sci 2011;73:255-61.

26. Suva MA, Kheni DB, Sureja VP. Aflapin®: A novel and selective 5-lipoxygenase inhibitor for arthritis management. Indian J Pain 2018;32:16-23.

27. Yu G, Xiang W, Zhang T, Zeng L, Yang K, Li J. Effectiveness of Boswellia and Boswellia extract for osteoarthritis patients: a systematic review and metaanalysis. BMC Complement Med Ther. 2020;20(1):225. doi: 10.1186/s12906-020-02985-6.

28. Sengupta K, Krishnaraju AV, Vishal AA, Mishr A, Trimurtulu G, Sarma KVS et al. Comparative efficacy and tolerability of 5-loxin ${ }^{\circledR}$ and aflapin ${ }^{\circledR}$ against osteoarthritis of the knee: A double blind, randomized, placebo controlled clinical study. International Journal of Medical Sciences https://doi.org/10.7150/ijms.7.366

2010;7(6):366-377

29. Vishal AA, Mishra A, Raychaudhuri SP. A double blind, randomized, placebo controlled clinical study evaluates the early efficacy of Aflapin ${ }^{\circledR}$ in subjects with osteoarthritis of knee. International Journal of Medical Sciences 2011;8(7):615-622. https://doi.org/10.7150/ijms.8.615

30. Krishnaraju AV, Sundararaju D, Vamsikrishna U, Suryachandra R, MacHiraju G, Sengupta K et al. Safety and toxicological evaluation of Aflapin $®$ : A novel Boswellia-derived anti-inflammatory product. Toxicology Mechanisms and Methods 2010; 20(9):556-563. https://doi.org/10.3109/15376516.2010.497978

31. Brien S, Lewith GT, McGregor G. Devil's Claw (Harpagophytum procumbens) as a treatment for osteoarthritis: a review of efficacy and safety. J Altern Complement Med 2006;12(10):981-93.

32. Winther K, Rein E, Kharazmi A. The anti-inflammatory properties of rose-hip. Inflammopharmacology 1999;7(1):63-8.

33. Kharazmi A, Winther K. Rose hip inhibits chemotaxis and chemiluminescence of human peripheral blood neutrophils in vitro and reduces certain inflammatory parameters in vivo. Inflammopharmacology 1999;7(4):377-86.

34. Winther K, Apel K, Thamsborg G. A powder made from seeds and shells of a rose-hip subspecies (Rosa canina) reduces symptoms of knee and hip osteoarthritis: a randomized, double-blind, placebo-controlled clinical trial. Scand J Rheumatol 2005;34(4):302-8.

35. Rein E, Kharazmi A, Winther K. A herbal remedy, Hyben Vital (stand. powder of a subspecies of Rosa canina fruits), reduces pain and improves general wellbeing in patients with osteoarthritis-A double-blind, placebocontrolled, randomised trial. Phytomedicine 2004;11(5):383-391.

https://doi.org/10.1016/j.phymed.2004.01.001 
36. Warholm O, Skaar S, Hedman E, Mølmen HM, Eik L. The effects of a standardized herbal remedy made from a subtype of Rosa canina in patients with osteoarthritis: A double-blind, randomized, placebo-controlled clinical trial. Current Therapeutic Research-Clinical and Experimental 2003;64(1):21-31. https://doi.org/10.1016/S0011-393X(03)00004-3

37. Christensen R, Bartels EM, Altman RD, Astrup A, Bliddal H. Does the hip powder of Rosa canina (rosehip) reduce pain in osteoarthritis patients? A meta-analysis of randomized controlled trials. Osteoarthritis and Cartilage. 2008; 16:965-972. 